\title{
Stress-strain state analysis of the leading car body of DPKr-2 diesel train under action of design and operational loads
}

\author{
Sergei Kostritsa ${ }^{1,}$, Alexander Pshinko ${ }^{1}$, Lyudmila Ursulyak $^{1}$, Andriy Kuzyshyn ${ }^{1,2}$, Maxim Kramarenko ${ }^{3}$, and Alex Grechkin ${ }^{3}$ \\ ${ }^{1}$ Dnipro National University of Railway Transport named after Academician V. Lazaryan, 49000 Dnipro, Ukraine \\ ${ }^{2}$ Lviv branch of Dnipro National University of Railway Transport named after Academician V. Lazaryan, 79052 Lviv, Ukraine \\ ${ }^{3}$ Public joint stock company «Kryukovsky Railway Car Building Works», 39621 Kremenchug, Ukraine
}

\begin{abstract}
Purpose. Provision of strength and durability of the main structural element of DPKr-2 diesel train - the leading car body. Methodology. A spatial solid-state 3-D model of the body is built and durability calculations are carried out concerning action of loads stipulated by regulatory documents operating in Ukraine. In particular, the following main estimated modes are considered: mode 1 - a notional safety mode which takes into account the possibility of considerable longitudinal forces arising during shunting movements, transportation and accidental collision; mode 2 - an operational mode which takes into account forces acting on a train during acceleration to constructional speed, coasting or braking from this speed while passing a curve. Results. Based on the results of theoretical and experimental studies a conclusion has been made that the leading car body construction of DPKr-2 diesel train meets the requirements of regulatory documents regarding strength and durability. Practical relevance. A complex of calculation and experimental work concerning assessment of stress-strain state of the leading car body of DPKr-2 diesel train under action of design and operational loads allowed the creation of construction which meets not only operational requirements but also strength and durability ones.
\end{abstract}

\section{Introduction}

Diesel trains are one of the main kinds of rolling stock which is successfully exploited in many countries of the world for suburban and interregional passenger transportation on unelectrified sections of railways. One of such latest developments of the national producer is
DPKr-2 diesel train designed and manufactured at Kryukovsky Railway Car Building Works.

DPKr-2 diesel train consists of three railcars: 2 leading cars of model 63-7083 and one intermediate car of model 63-7084 (Fig. 1).

The main technical characteristics of DPKr-2 diesel train are given in Table 1.

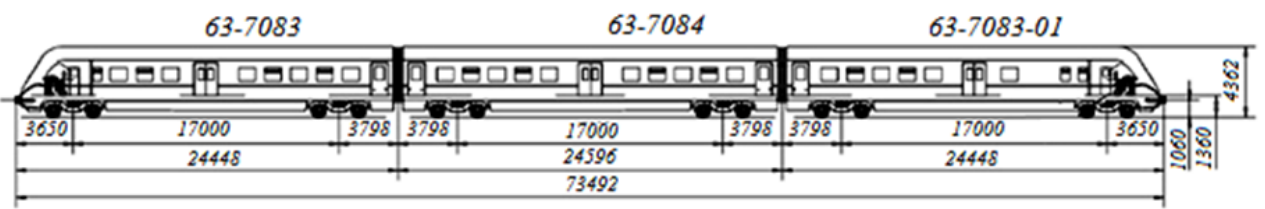

Fig. 1. Scheme of DPKr-2 diesel train

Table 1. Main characteristics of DPKr-2 diesel train.

\begin{tabular}{|c|c|}
\hline Parameter, dimensionality & Standard for a car \\
\hline Track width, $\mathrm{mm}$ & 1520 \\
\hline Car gauge according to GOST 9238 & $\mathrm{~T}$ \\
\hline $\begin{array}{c}\text { Car framework, mm } \\
\text { - leading car, model 63-7083 } \\
\text { - intermediate car, model 63-7084 }\end{array}$ & $\begin{array}{l}17000 \\
17000\end{array}$ \\
\hline Car width, $\mathrm{mm}$ & 3500 \\
\hline Car height, $\mathrm{mm}$ & 4400 \\
\hline $\begin{array}{l}\text { Height of automatic hitch axis from the } \\
\text { top of rails, } m m\end{array}$ & $1060 \pm 20$ \\
\hline $\begin{array}{c}\text { Car length along the hitch axes: } \\
\text { - leading, } \mathrm{mm} \\
\text { - trailer, } \mathrm{mm}\end{array}$ & $\begin{array}{l}24596 \\
24596\end{array}$ \\
\hline Passenger capacity/number of seats, pc: & $637 / 289$ \\
\hline
\end{tabular}

\begin{tabular}{|c|c|}
\hline Car tare-weight, $\mathrm{t}:$ & 63,5 \\
car of model 63-7083 & 61,2 \\
car of model 63-7084 & \\
\hline $\begin{array}{c}\text { Maximum static pressure of a wheelset } \\
\text { on the rails, tf: }\end{array}$ & 20 \\
- leading car & 20 \\
\hline - intermediate car & $3 \times 390$ \\
\hline Engine unit capacity, $\mathrm{kW}$ & 140 \\
\hline Maximum operating speed, $\mathrm{km} / \mathrm{h}$ & up to 1000 \\
\hline Length of turnover section, $\mathrm{km}$ & high -1100 \\
\hline Height of boarding platforms from the & low -200 \\
\hline top of rail, mm millimeters & 1000 \\
\hline Amount of fuel in every car, 1 & \\
\hline
\end{tabular}

To provide operation reliability and safety of DPKr-2 diesel train, specialists of Dnipro National University of

* Corresponding author: kossa571@gmail.com 
Railway Transport and PJSC "Kryukovsky Railway Car Building Works" have conducted a complex of theoretical and experimental studies, in course of which the conformity of diesel train construction to the requirements of regulatory documents operating in Ukraine [1-2] and the requirements of statement of work has been checked. One of the main kinds of studies mentioned above was the assessment of strength, including fatigue strength, of the main loadbearing elements of DPKr-2 diesel train - frames of body and bogies.

The complex of calculation and experimental work of stress-strain assessment of the bogie frames of DPKr-2 diesel train under action of design and operational loads is outlined in work [3]. General issues related to design, manufacturing and putting into operation of new types of bogie frames of self-propelled rolling stock in the countries of the European Union are presented in works [4-7].

Quite a big number of works, e.g. [7-13], are devoted to the issues of theoretical and experimental research of strength and durability of welded car bodies, but none of them uses legal framework for multiple unit rolling stock operating in Ukraine.

\section{Research methodology}

To assess the strength of railway rolling stock, including self-propelled one, a legal framework based on fundamental research in the field of material fatigue is used in Ukraine and abroad. However, criteria for this assessment differ qualitatively. In particular, in Ukraine the fatigue strength assessment is carried out using fatigue safety factor [1-2] which should not exceed the normative value. In EU countries the fatigue strength assessment is carried out upon allowable stresses, which, in turn, are determined using ultimate stress charts [14-15]. In work [16] a comparison of the regulatory documents mentioned above is conducted which leads to the conclusion about good convergence of results obtained with regard to standards applicable in Ukraine and EU countries.

Strength assessment, including fatigue strength one, of DPKr-2 diesel train leading car was conducted according to the requirements [1] in two steps:

- theoretical studies aimed at choosing parameters of main load-bearing elements of the body and establishing installation positions of measuring devices during tests; - experimental studies (static strength tests, navigation strength tests and collision tests) aimed at determining actual parameters characterizing the construction strength.

While dimensioning a diesel train car the ANSYS Workbench [17-18] package of applications (PA) is used which is characterized by a high degree of strength calculation automation at the stage of project-related research. This PA permits any combination of static pressures and allows for stress state at the elastic stage of both the whole car body construction and its separate nodes to be analyzed with a different degree of detailing.

An estimated 3-D model of the leading car body designed with the help of the ANSYS package of applications (PA) is presented in (Fig. 2). The model contains 1071131 elements and 1646383 nodes.

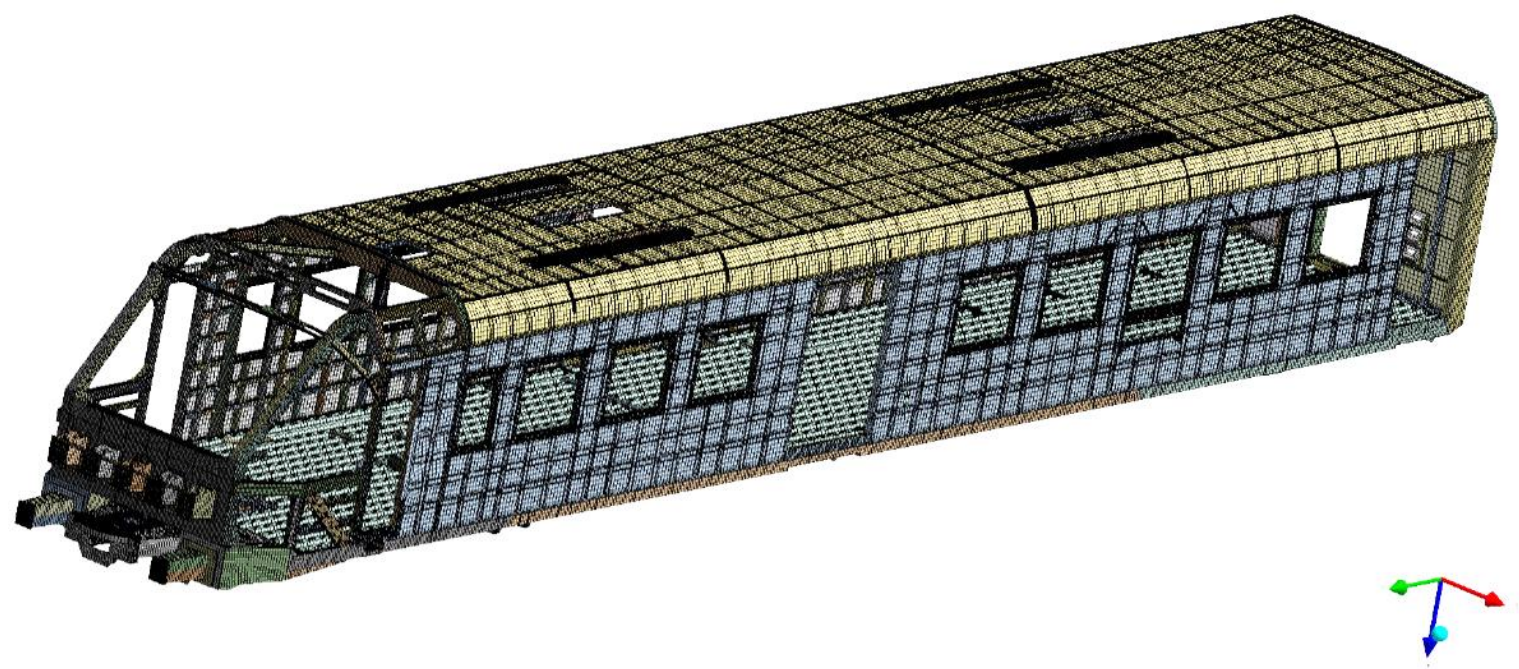

Fig. 2. Estimated 3-D model of the leading car body of DPKr-2 diesel train

Separately, the above given estimated scheme of the body is presented by a set of substructures integrated into a general estimated scheme. This approach allowed an independent preparation and adjustment of input data to be made for each substructure. After that system assembly and task solution can be performed. While designing the finite-element model of the body, flat quadrangular and triangular finite elements were used and an assumption was introduced that the construction material works in the elastic stage of deformation and has permanent characteristics - modulus of elasticity $\mathrm{E}=2,0 \cdot 10^{5} \mathrm{Mpa}$ and Poisson's ratio $\mu=0,3$ [19]. Car resting on bogie is presented in the estimated scheme by introduction of kinematic links into nodes which correspond to the support. 
Car strength, according to [1], is calculated for 2 main estimated modes:

Mode 1 - a notional safety mode. This mode takes into account the possibility of considerable longitudinal forces arising during shunting movements, transportation and accidental collision;

Mode 2 - an operational mode which takes into account forces acting on a train during acceleration to constructional speed, coasting or braking from this speed while passing a curve.

During calculation for mode 1 the following main forces were applied to the estimated model:

- normative longitudinal compressive force of $1500 \mathrm{kN}$ acting along automatic hitch axes;

- gross gravitational force of the body of $699 \mathrm{kN}$, in this case gravitational forces of equipment elements were applied at the points of their attachment to the body framework.

During calculation for mode 2:

- normative longitudinal tensile force of $800 \mathrm{kN}$;

- longitudinal inertia forces acting on separate nodes and elements which were identified by multiplying their mass by acceleration of the body;

- gross gravitational force of the body of $699 \mathrm{kN}$;

- vertical dynamic force which was identified by multiplying gross gravitational force of the body by the normative value of vertical dynamics ratio in the second stage of hanging which equals 0.2 ;

- centrifugal inertia force of the body proceeding from undamped acceleration while moving around a curve which equals $0,7 \mathrm{~m} / \mathrm{s}^{2}$.

Strength assessment for mode 1 was carried out upon allowable stresses, for mode 2 - upon allowable stresses and fatigue safety factor. Allowable stresses for estimated modes 1 and 2 are given in table 5.1 of standards [1].

To determine fatigue safety factor $n$ the following proportion was used:

$$
n=\frac{\sigma_{-1}}{k \sigma_{v}+\psi \sigma_{m}},
$$

where $\sigma_{-1}-$ endurance limit of a standard sample in the symmetrical cycle of loading which was chosen depending on the steel grade using table 5.2 of standards [1];

$\sigma_{m}-$ average stress of a cycle which was determined in every structural element under action of gross vertical static load;

$\sigma_{v}$ - amplitude of dynamic stresses which was identified from the proportion $\sigma_{v}=k_{d} \sigma_{m}$, where $k_{d}$ - vertical dynamics ratio in the second stage of suspension. On the basis of dynamic calculation results [20] of a diesel train $k_{d}<0,1$. Normative (maximum permissible) value of vertical dynamics ratio is 0,2 .
Therefore during calculation the maximum value of $k_{d}=0,2$ was accepted;

$\psi \quad-\quad$ a coefficient reflecting the sensitivity of a metal to cycle asymmetry (if $\sigma_{m}>0 \psi=0,3$, if $\sigma_{m}<0 \psi=0$ );

$k$ - effective coefficient reflecting endurance reduction of a detail in relation to endurance limit of a standard sample.

Coefficient $k$ was determined from the proportion:

$$
k=\beta_{k} \frac{k_{1} k_{2}}{\gamma m},
$$

where $\beta_{k}-$ effective coefficient of stress concentration was accepted as equal to 1 ;

$k_{1}$ - coefficient reflecting material heterogeneity of the detail, for rolling $k_{1}=1,1$

$k_{2}$ - coefficient reflecting the influence of inner stresses in the detail depending on detail size $k_{2}=1,0 \ldots 1,2$;

$\gamma$ - coefficient reflecting the detail sizes which was determined according to the graph given in figure 3,5 of standards [1];

$m$ - coefficient reflecting the surface state of a detail, for rolling $m=0,8$.

According to requirements [1], fatigue safety factor must be not less than normative value -2 .

Based on conclusions from the analysis of calculation results for modes 1 and 2, installation positions of measuring devices during static strength tests, navigation strength tests and collision tests were established.

\section{Research results}

Figure 3 illustrates fields of equivalent (according to the Mises-Hencky theory) stresses in the structure of the leading car body of DPKr-2 diesel train as well as nodes in which there are maximum stresses under action of loads corresponding to estimated mode 1 .

Table 2 presents allowable stress values and maximum stresses obtained as a result of calculation for estimated mode 1 .

The presented results show that under loads simulating accidental collision and shunting movements maximum stresses in the most loaded elements of the body construction do not exceed allowable values, i.e. strength in estimated mode 1 is ensured.

Figure 4 illustrates fields of equivalent (according to the Mises-Hencky theory) stresses in the structure of the leading car body of DPKr-2 diesel train as well as nodes in which there are maximum stresses under action of loads corresponding to estimated mode 2 .

Table 3 presents allowable stress values, maximum stresses and fatigue safety factors obtained as a result of calculation. 


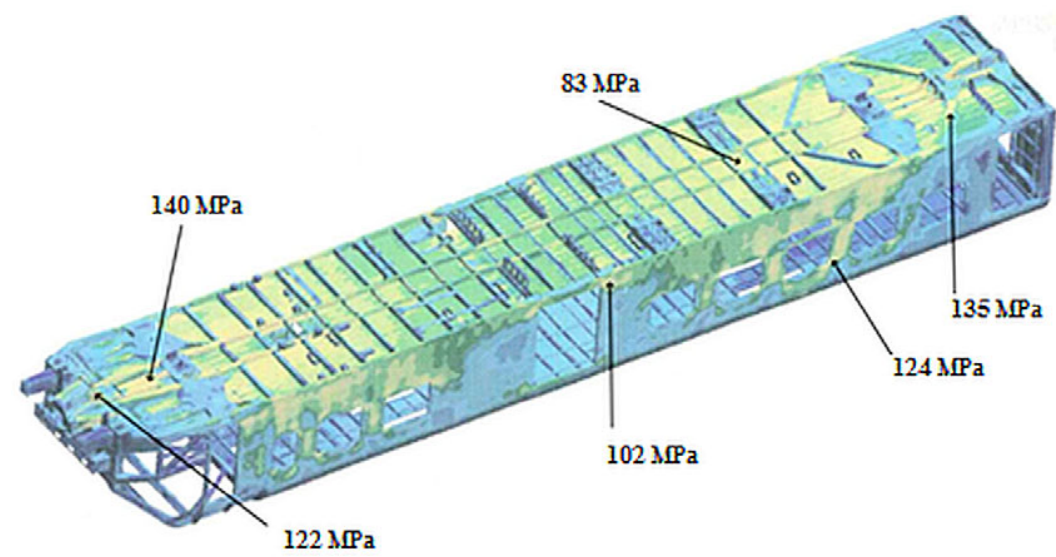

Fig. 3. Stress state of the structure of the leading car body of DPKr-2 diesel train under action of loads corresponding to estimated mode 1 (view from below)

Table 2. Maximum stresses in the main structural elements of the body under action of loads corresponding to estimated mode 1.

\begin{tabular}{|c|c|c|c|}
\hline Structural element of the body & Steel grade & $\begin{array}{c}\text { Allowable } \\
\text { stresses, } \mathrm{mPa}\end{array}$ & $\begin{array}{c}\text { Equivalent } \\
\text { stresses, } \mathrm{mPa}\end{array}$ \\
\hline \multicolumn{4}{|c|}{ Underframe } \\
\hline Spine beam (head part) & $325-09 \Gamma 2 \mathrm{C}$ & 292 & 122 \\
\hline Centre bearer & $295-09 \Gamma 2 \mathrm{C}$ & 265 & 140 \\
\hline End girder & $345-09 \Gamma 2 \mathrm{C}$ & 327 & 93 \\
\hline Cantilever unit diagonals & $345-09 \Gamma 2 \mathrm{C}$ & 327 & 135 \\
\hline "Power pack" mount beams & $345-09 \Gamma 2 \mathrm{C}$ & 327 & 85 \\
\hline \multicolumn{4}{|c|}{ Side wall } \\
\hline Window opening vertical struts & 08X18H10 & 194 & 127 \\
\hline Doorway vertical struts & 08X18H10 & 194 & 102 \\
\hline Lower door beam & $08 \mathrm{X} 18 \mathrm{H} 10$ & 194 & 88 \\
\hline \multicolumn{4}{|c|}{ Cab framework } \\
\hline Cab door step & $345-09 \Gamma 2 \mathrm{C}$ & 327 & 95 \\
\hline Doorway pillar & $345-09 \Gamma 2 \mathrm{C}$ & 327 & 83 \\
\hline \multicolumn{4}{|c|}{ Roof } \\
\hline Longitudinal beam & 08X18H10 & 194 & 39 \\
\hline Cross-beam & 08X18H10 & 194 & 37 \\
\hline Air conditioner support & $08 \mathrm{X} 18 \mathrm{H} 10$ & 194 & 42 \\
\hline
\end{tabular}

Note to table 2. Low alloy steel 09G2S is an analogue of European steel DIN 16Mn6, stainless steel 08X18H10 - European steel DIN 1.4301.

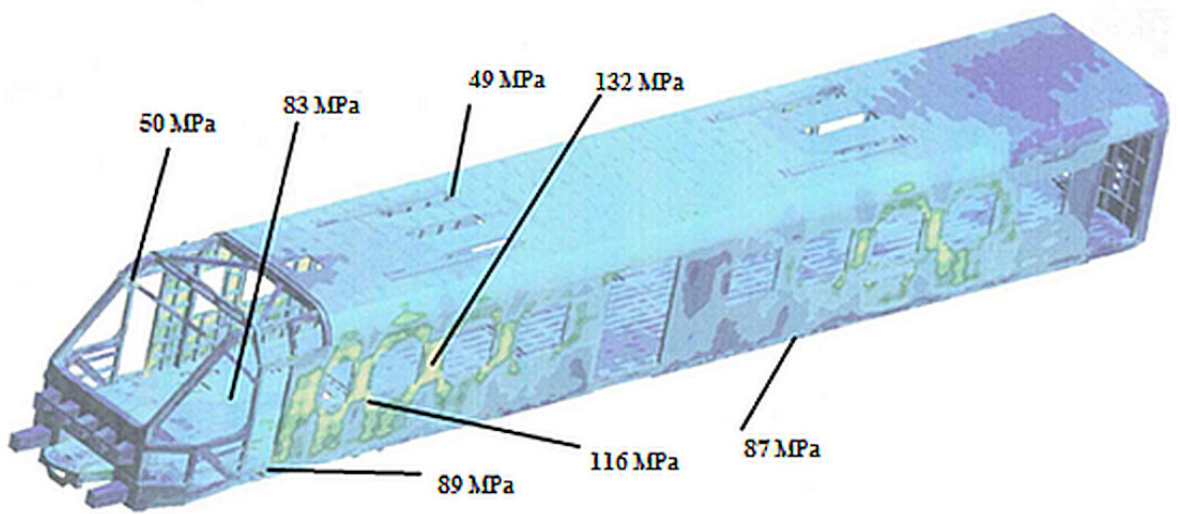

Fig. 4. Stress state of the structure of the leading car body of DPKr-2 diesel train under action of loads corresponding to estimated mode 2. 
Table 3. Maximum stresses in the main structural elements of the body and fatigue safety factors under action of loads corresponding to estimated mode 2 .

\begin{tabular}{|c|c|c|c|c|}
\hline Structural element of the body & Steel grade & $\begin{array}{c}\text { Allowable } \\
\text { stresses, } \mathrm{mPa}\end{array}$ & $\begin{array}{c}\text { Equivalent } \\
\text { stresses, } \mathrm{mPa}\end{array}$ & $n$ \\
\hline \multicolumn{5}{|c|}{ Underframe } \\
\hline Spine beam (head part) & $325-09 \Gamma 2 \mathrm{C}$ & 205 & 103 & 3,1 \\
\hline Centre bearer & $295-09 \Gamma 2 \mathrm{C}$ & 195 & 83 & 3,6 \\
\hline Side rail (the middle of the wagon) & $325-09 \Gamma 2 \mathrm{C}$ & 205 & 62 & 5,1 \\
\hline "Power pack" mount beams & $345-09 \Gamma 2 \mathrm{C}$ & 220 & 92 & 3,6 \\
\hline Stair mechanism cross-beam & $345-09 \Gamma 2 \mathrm{C}$ & 220 & 80 & 4,1 \\
\hline \multicolumn{5}{|c|}{ Side wall } \\
\hline Vertical strut & 08X18H10 & 138 & 112 & 2,6 \\
\hline Strut under window & 08X18H10 & 138 & 96 & 3,0 \\
\hline Upper window opening beam & 08X18H10 & 138 & 76 & 3,6 \\
\hline Lower window opening beam & 08X18H10 & 138 & 87 & 3,3 \\
\hline \multicolumn{5}{|c|}{ Cab framework } \\
\hline Cab door step & $345-09 \Gamma 2 \mathrm{C}$ & 220 & 89 & 3,7 \\
\hline Inclined beam of the cab & $345-09 \Gamma 2 \mathrm{C}$ & 220 & 50 & 5,7 \\
\hline \multicolumn{5}{|c|}{ Roof } \\
\hline Longitudinal beam & $08 \mathrm{X} 18 \mathrm{H} 10$ & 138 & 36 & 7,9 \\
\hline Air conditioner support & 08X18H10 & 138 & 49 & 5,8 \\
\hline
\end{tabular}

The analysis of stress state of the leading car body shows that maximum stresses in the most loaded elements of body construction do not exceed allowable values and fatigue safety factor is significantly higher than the normative value 2 .

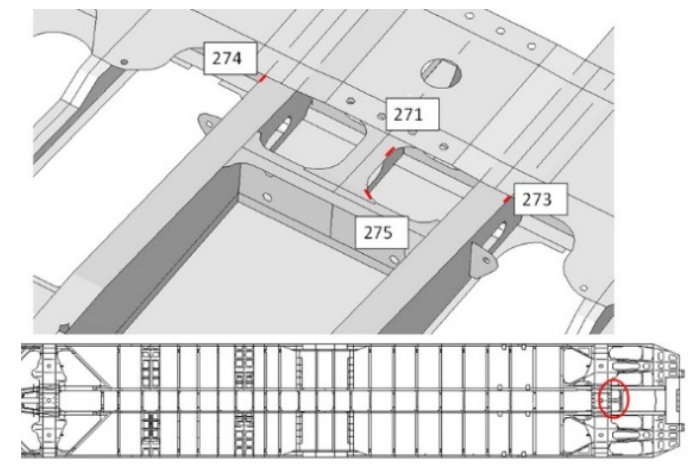

Based on the results of theoretical studies described above, a strain gauge layout chart has been developed for the purpose of conducting static strength tests, navigation strength tests and collision tests. Figures 5-7 illustrate examples of strain gauge layout during the testing mentioned above.

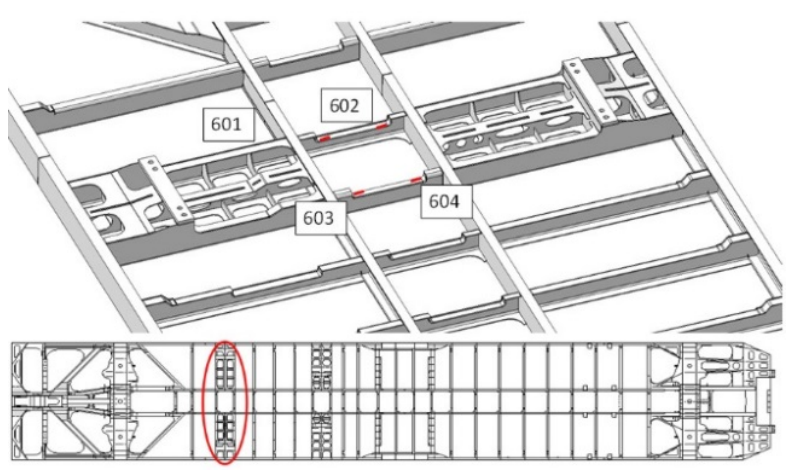

Fig. 5. Strain gauge layout on the underframe
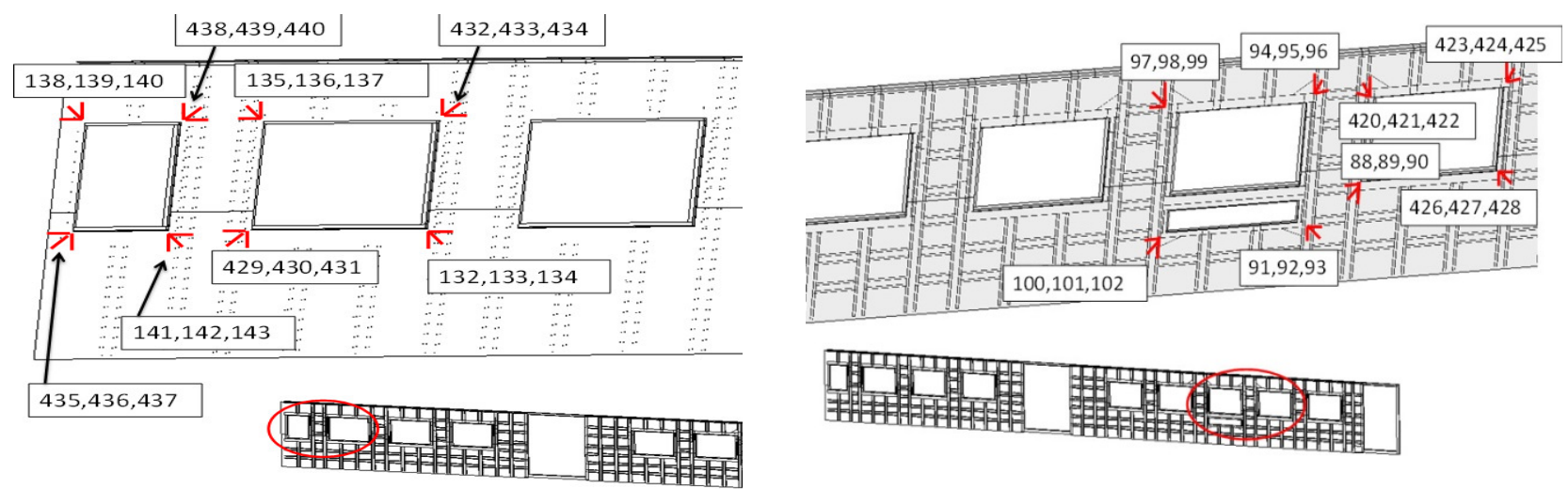

Fig. 6. Strain gauge layout on the side walls 

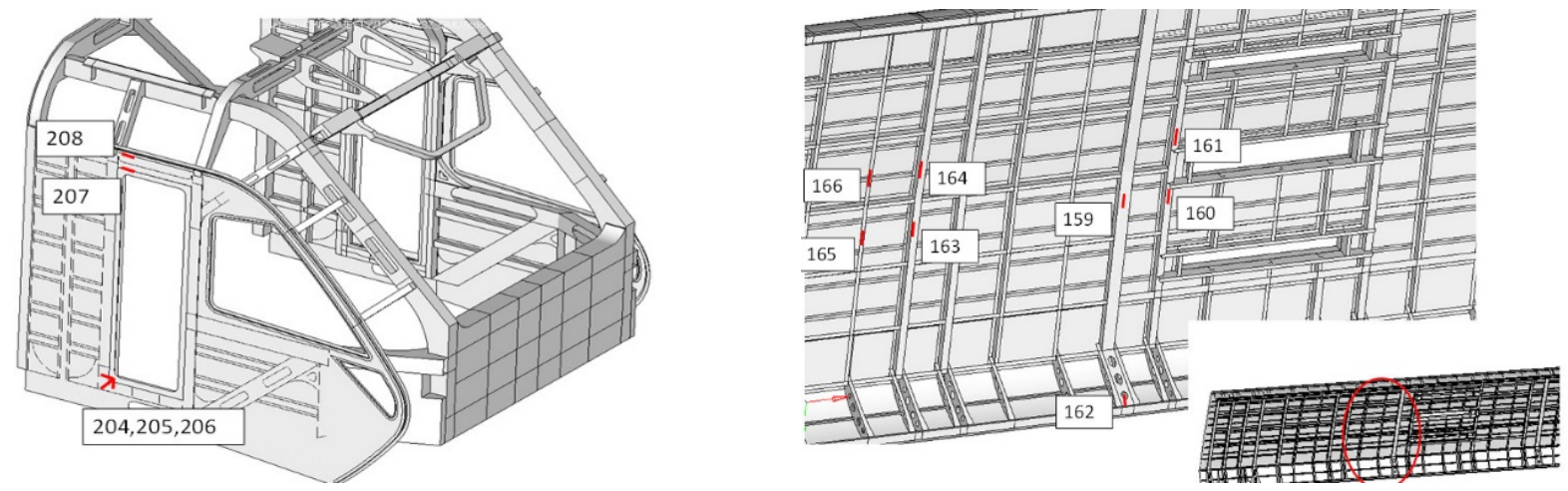

Fig. 7. Strain gauge layout on the cab framework and roof

The analysis of static strength testing and navigation strength testing results showed that the minimum value of fatigue safety factor occurs in the area of power unit fastening to the underframe and equals 3.7 (point 252, Fig. 5).

According to the collision testing results, the most loaded is the junction area of spine and longitudinal beams where stresses reached the values of $210 \mathrm{mPa}$ (points 271, 275 , Fig. 5) with the force of impact of $1750 \mathrm{kN}$.

On the basis of theoretical and experimental research results it was concluded that the construction of the leading car body of DPKr-2 diesel train meets the requirements of regulatory documents against the criteria of strength including fatigue one.

\section{Scientific novelty and practical relevance}

1. For the first time a spatial finite-element model of a diesel train body of a new generation is built and calculation of strength under action of standard loads is made.

2. An estimated scheme of the body is presented by a set of substructures integrated into a general estimated scheme. This modular approach made it possible to make an independent preparation and adjustment of input data for each substructure and after that perform the system assembly and task solution.

3. Modular approach to the estimated scheme design makes it possible to use it for the strength assessment of the body of diesel trains of new generations changing only the structural elements that are subject to upgrading.

\section{Conclusions}

The complex of calculation and experimental work on stress-strain state assessment of the leading car body frame of DPKr-2 diesel train under action of design and operational loads made it possible to create a construction that meets both operational standards and strength and durability requirements.

\section{Bibliography}

1. Regulations on calculation and assessment of the strength of load-bearing elements and the dynamic qualities of multiple units, Moscow, 146 p. (1997)

2. DSTU 4493: 2005 Wagons of long-distance passenger diesel and electric trains. Security requirements, Kiev, State standard of Ukraine, $16 \mathrm{p}$

3. S. Kostrytsia, S. Molchanov, M. Kramarenko, A. Hrechkin, D. Laktionov Stress-strain state assessment of the bogie frame of DPKr-2 diesel train under action of design and operational loads, Science and Transport Progress. Bulletin of Dnipropetrovsk National University of Railway Transport, №.1(79), pp 128-138 (2019)

4. B. Li, Y. Zhao Strength assessment for bogie frame based on UIC standard, Machinery, №10, pp 9-12 (2012)

5. T-S. Jung-Won, H. Hyun-Moo, J. Hyun-Kyu Fatigue Design Evaluation of Railway Bogie with Full-Scale Fatigue, Advances in Materials Science and Engineering, pp. 1-11 (2017)

6. M. Kassner Fatigue strength analysis of a welded railway vehicle structure by different methods, International journal of fatigue, №34, pp. 103-111 (2012)

7. EN 13749:2011 Railway applications - wheel sets and bogies-methods of specifying structural requirements of bogie frames, European Committee for Standardization, (2011)

8. A. Shukri, D. Willem, Y. Anas Modeling aspects of the design of railway vehicle structures and their crashworthiness, Proceedings of the Institution of Mechanical Engineers, Part F: Journal of Rail and Rapid Transit, №230 (6), pp. 1575-1589 (2016)

9. M. Płaczek, A. Wróbel, A Baier Computer-aided strength analysis of the modernized freight wagon Modern Technologies in Industrial Engineering (ModTech2015), IOP Conf. Series: Materials Science and Engineering 95, (2015)

10. D. Peng, R. Jones, T. Constable Tools and methods for addressing the durability of rolling stock, Engineering failure analysis, №34, pp. 278-289 (2013) 
11. S. Slavchev, V. Stoilov, S. Purgic Static strength analysis of the body of a wagon, Journal of the Balkan Tribological Association, №21 (1), pp. 38-57 (2015)

12. O. Fomin, J. Gerlici, A. Lovskaya, K. Kravchenko, P. Prokopenko, A. Fomina, V. Hauser Research of the strength of the bearing structure of the flat wagon body from round pipes during transportation on the railway ferry, Horizons of Railway Transport 2018, MATEC Web of Conferences 235, (2018)

13. P. Št'astniak, M. Moravčík, L. Smetanka Investigation of strength conditions of the new wagon prototype type Zans, MATEC Web of Conferences 254, (2019)

14. ERRI B12/RP17 Programme of Stresses to be carried out on Wagons with Steel Underframe and Body Structure, European Rail Research Institute, №8 (1996)

15. EN 12663:2010 Railway applications - Structural requirements of railway vehicle bodies - Part 1: Locomotives and passenger rolling stock (and alternative method for freight wagons), European Committee for Standardization, (2011)

16. S. Kostrytsya Assessment of fatigue strength of a selfpropelled rolling stock on the results of certification tests in Ukraine and the EU, Railway problems. Railway reports, №61, pp. 29-36 (2017)

17. K. Bosov Ansys for constructors. DMK Press, 248 p. (2016)

18. A. Kaplun Ansys in the hands of an engineer. Practical guide, Librokom, 270 p. (2016)

19. G. Pisarenko, A. Yakovlev, V. Matveev Handbook of resistance to materials, Science. Dumka, Kiev, 165 p. (1988)

20. A. Kuzyshyn, A. Batig, S. Kostritsa [et al.] Research of safety indicators of diesel train movement with two-stage spring suspension, BulTrans 2018: 10th Intern. Sci. Conf. on Aeronautics, Automotive and Railway Engineering and Technologies. - Sozopol: 234 (2018) 